\title{
Editorial so
}

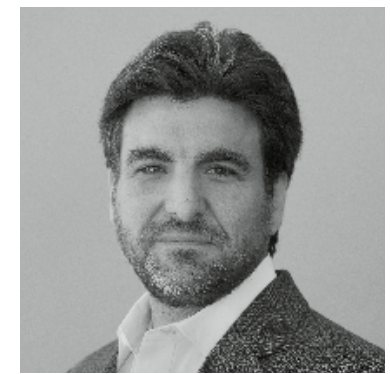

Marketers have traditionally - and almost instinctively - avoided political controversy at all costs. Although they might trumpet their efforts to tackle societal challenges such as hunger, poverty or workplace safety, the line has always been drawn on polarizing issues, especially those which are contested in the political world. Why would an organization want to invite that sort of controversy, the logic goes. Sure, taking a political position may appeal to some customers, but it will almost surely alienate others. When basketball legend and megabrand Michael Jordan was asked in the 1980's why he wasn't using his platform to influence political opinions, he famously quipped, "Republicans buy sneakers too." Although he recalls it being said in jest, it perfectly sums up the prevailing wisdom at that time.

But something radical is happening in the marketing world. Marketers are throwing that caution to the wind. Major brands around the world are increasingly taking stands on contentious issues such as LGBTQ, racial injustice, and climate change. Perhaps, even more surprising, some brands are using these stands as important cornerstones of their communications campaigns. For example, Netflix plastered metro stations with outdoor advertising stating that "Rainbow is the new Black." And Unilever's Ice Cream brand Ben \& Jerry's launched a flavor called "Justice Remix'd" as a way to raise awareness and support for criminal justice reform.

Are brands that take a more activist posture on political issues doing the right thing? Many of the world's brightest minds are looking into it. The picture that is emerging is that such brand activism is as complex and multi-faceted as it is novel. This issue of NIM Marketing Intelligence Review showcases insights from some of the best research to date. The articles suggest that brand activism is here to stay.

Just as important, this issue provides guidance on how marketers should think about politics and how to successfully implement brand activism strategies. The articles cover not only consumer reactions to brand activism, but also the reactions of investors, employees, and politicians. In all, you'll find a 360-degree view of one of today's most exciting and important topics.

I hope you enjoy this issue!

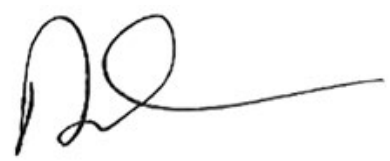

Daniel Korschun

Philadelphia, July 2021 